\title{
Erratum to: A Study of Soil Organic Matter Stability Using Derivatography and Long-Term Incubation Methods
}

\author{
D. A. Sokolov ${ }^{a}$, I. I. Dmitrevskaya ${ }^{b}$, N. B. Pautova ${ }^{a}$, T. N. Lebedeva ${ }^{a}$, \\ V. A. Chernikov ${ }^{b}$, and V. M. Semenov ${ }^{a, *}$ \\ ${ }^{a}$ Institute of Physicochemical and Biological Problems of Soil Science, Russian Academy of Sciences, \\ Pushchino, Moscow oblast, 142290 Russia \\ ${ }^{b}$ Russian State Agrarian University-Moscow Timiryazev Agricultural Academy, Moscow, 127550 Russia \\ *e-mail:v.m.semenov@mail.ru \\ Received June 16, 2021; revised June 16, 2021; accepted June 16, 2021
}

DOI: $10.1134 / \mathrm{S} 1064229321770015$

The article "A Study of Soil Organic Matter Stability Using Derivatography and Long-Term Incubation Methods”, written by D.A. Sokolov, I.I. Dmitrevskaya, N.B. Pautova, T.N. Lebedeva, V.A. Chernikov, and V.M. Semenov, was originally published electronically in Springer-Link on 29 April 2021 without Open Access. After publication in volume 54, issue 4, pages 487-498 the authors decided to make the article an Open Access publication. Therefore, the copyright of the article has been changed to (C) The Author(s) 2021 and the article is forthwith distributed under the terms of a Creative Commons Attribution 4.0 International License (http://creativecommons.org/licenses/by/4.0/, CC BY), which permits use, duplication, adaptation, distribution and reproduction of a work in any medium or format, as long as you cite the original author(s) and publication source, provide a link to the Creative Commons license, and indicate if changes were made.

The original article can be found online at https://doi.org/10.1134/S1064229321040141 